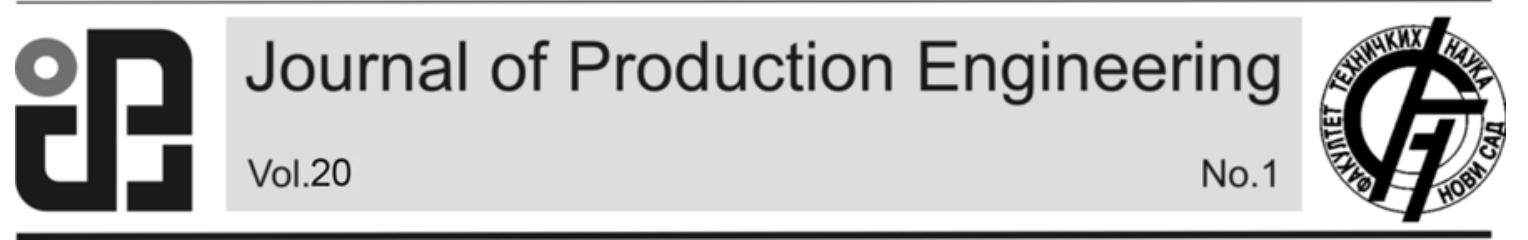

JPE (2017) Vol.20 (1)

Sodhi, H S.

Original Scientific Paper

\title{
PARAMETRIC OPTIMIZATION OF ELECTRIC DISCHARGE MACHINE USING RESPONSE SURFACE METHOD
}

Received: 09 December 2016 / Accepted: 01 March 2017

\begin{abstract}
Present work has been done for the parametric optimization of process parameters such as discharge current, pulse on time, gap voltage and duty cycle on a Electric Discharge Machine for high speed steel for getting maximum material removal rate and at the same time to get minimum surface roughness. Experiments has been performed an a matrix formulated by Response Surface Method and further analysis work has been done by using regression test and ANOVA to get the optimized range of parameters to get the desired results on EDM machine.
\end{abstract}

Key words: Electric Discharge Machine, surface roughness, optimization.

Parametarska optimizacia mašine za elektroerozionu obradu pomoću metode odzivne površine. $U$ ovom radu je urađena optimizacije parametara na mašini kao što su struje pražnjenja, puls u vremenu, napon prekida i radnog ciklusa na mašina za elektroerozionu obradu za obradu brzoreznog čelika u cilju dobijanja maksimalne količine skidanja materijala i istovremeno dobijanje minimalne površinske hrapavosti. Eksperimenti su izvedeni prema matrici metode odziva površine, a dalje analize su urađene pomoću testa regresije i ANOVA analize da se dobije optimalni opseg parametara, odnosno da bi se dobili željeni rezultati na EDM mašini.

Ključne reči: mašina za elektroerozionu obradu, hrapavost površine, optimizacija.

\section{INTRODUCTION}

Electric discharge machine is electro-warm machining process, in which electric vitality is utilized to produce the start between the work piece and terminal. The material is expelled because of warm vitality which is created by the electric start. Electric release machine is utilized for a machining of high quality temperature safe combinations and the material which are hard to machine in other machining forms. In EDM, since there is no immediate contact between the work piece and the cathode, consequently there are no mechanical powers existing between them. Any kind of conductive material can be machined utilizing EDM independent of hardness or sturdiness of material.

Each assembling industry expect the most astounding material evacuation rate and at same time least device wear rate and least surface harshness. Keeping in mind the end goal to accomplish that it is critical to streamline the EDM procedure parameters. The procedure parameters of EDM which impact these reactions are release current, voltage, beat on-time, beat off-time, obligation cycle, circular segment crevice, breadth of terminal, overcut, ecological conditions, coolant utilized, administrator abilities and so forth. In the present work, the advancement of four EDM handle parameters like release current, beat on -time, voltage and obligation cycle for high Speed steel (AISI-M2) is finished by performing tests utilizing reaction surface method (RSM) with a specific end goal to amplify the material expulsion rate and at same time minimize the apparatus wear and minimize the surface unpleasantness. After the improvement results are evaluated through ANOVA test.

\section{ELECTRIC DISCHARGE MACHINE}

The universe of metal working has made considerable progress. Previously, smithy were compelled to sledge bits of metal, yet in this new age, we have a fast procedure to shape the metal to our plan. So EDM is one of them assembling process where coveted shape is accomplished utilizing sparkles or electrical release. Fundamentally there are two sorts of EDM machine: 1. Die sinking EDM

\section{Wire EDM}

In this trial work the machine utilized is electronica's elecktra puls PS 50 which is bite the dust sinking EDM.

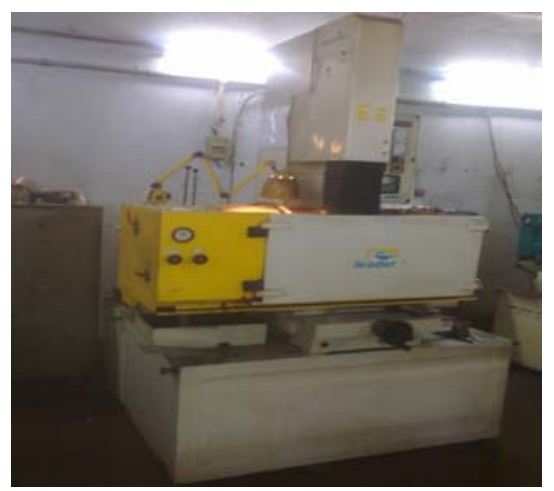

Fig. 1. Electronica's elecktra puls PS 50 electric discharge machine

\section{PROCESS PARAMETERS FOR EDM}

In this experiment, the effect of following process parameters have been taken into account to measure the material removal rate, tool wear rate and surface roughness. 


\subsection{Discharge Current}

It is one of most critical machining parameter in EDM in light of the fact that it identifies with power utilization while machining. The release current is specifically corresponding to material evacuation rate. Higher current will enhance material evacuation rate yet at the cost of hardware wear rate and surface harshness. It is measured in amp permitted to per cycle.

\subsection{Pulse-On-Time}

It is span of time in small scale seconds( $\mu s)$ when the current is permitted to stream per cycle. Material evacuation rate is additionally specifically relative to measure of vitality connected amid this on-time. This vitality is truly controlled by the pinnacle current and length of on-time.

\subsection{Gap Voltage}

It is the open circuit voltage which is connected between the terminals. The release voltage de-ionizes the dielectric medium, which rely on cathode hole and the quality of di-electric, preceding stream of current. Once the present stream begin, the open circuit voltage drops and balance out the anode hole. It is fundamental element that impacts the start vitality, which is in charge of higher material expulsion rate.

\subsection{Duty Cycle}

It is the proportion of heartbeat on-time and the beat time frame. Obligation cycle is characterized as a condition given beneath:

$$
\text { Tau }=\frac{\text { ton }}{\text { ton }+ \text { toff }} \times 100
$$

At higher Tau, the spark energy is supplied for longer duration of the pulse period which resulting in higher machining efficiency.

\section{INTRODUCTION TO RESPONSE SURFACE METHOD (RSM)}

Response surface methodology (RSM) is gathering of scientific and factual system for exact model building. The goal is to upgrade the a response (output factors) which is impacted by a few free factors (input factors). Reaction surface system involves an assortment of strategies for investigating for ideal working conditions through test techniques. Ordinarily, this includes doing a few trials, utilizing aftereffect of one trial to give bearing to what to do next. This next activity could be to center the trial around an alternate arrangement of conditions, or to gather more information in current test area to fit a higher request demonstrate or affirm what appears to have found. The use of RSM is likewise planned to lessen the costs of other troublesome expository methods (like: limited component technique, or CFD investigation and so on.) and their related numerical noises. The issue can be approximated with smooth elements of focal composite outline of RSM that enhance the joining of the advancement procedure since they diminish the impact of commotions and characteristic blunders, generously. The reactions can be spoken to graphically, either in three dimensional space or as shape plots that further picture connection of reaction surfaces with information factors all the more obviously.

\section{LITERATURE REVIEW}

Lee et al. [1] have done test and found that the aftereffects of MRR and surface harshness increments with the estimations of heartbeat current however after certain esteem SR and MRR decrease due to development of electric plasma. Bhattacharyya et al. [2] has created scientific models for surface harshness, white layer thickness and surface split thickness in light of reaction surface philosophy (RSM) approach using test information. M.M. Rahman et al. [3] explored the impact of the pinnacle current and heartbeat term on the execution qualities of the EDM. I. Rajurkar et al. [4] did comes about which demonstrated that the force and heartbeat time variable were the most essential if there should arise an occurrence of SR while the obligation cycle component was not noteworthy by any stretch of the imagination. The power consider was again compelling instance of TWR. The imperative calculates instance of MRR were the force took after by obligation cycle and the beat time. Bhattacharyya.B et al. [5] explored the machining of tungsten carbide with copper tungsten as anode. The full factorial outline of examinations was utilized for breaking down the parameters. In the event of SR, the vital elements were voltage and heartbeat off time while current and heartbeat on time were not huge. curre D. Kanagarajan et al. [6] found that SR of work piece and terminal were impacted by current and heartbeat on time, higher estimations of these parameters expanded the surface unpleasantness. Rahman M.M et al. [7] arrived at the accompanying conclusions: with increment in pinnacle current MRR, TWR and ROC expanded altogether in a nonlinear manner; MRR and ROC expanded with the expansion in heartbeat on time and hole voltage was found to have some impact on the three reactions. Chen. S. L et.al [8] concentrated the impacts of EDM parameters on surface qualities of a sort of tungsten carbide. They have reasoned that MRR and surface unpleasantness of the work piece are specifically corresponding to the release current power. Puertas I.,. [9] utilized non-overwhelmed sorting hereditary calculation (NSGA-II) to acquire a Pareto ideal arrangement of info factors in an exchange off way. Sodhi H S etal Discussed that in present manufacturing scenario, quality and quantity are two challenging aspects to be looked upon. Quality is important according to customer point of view, whereas quantity is required for the industry to maximise profit earnings. For the sustainability of machining industry, there should be an optimised path which should be followed to satisfy not only the aspect of higher material removal rate (MRR) but also to achieve lower surface roughness (Ra) simultaneously. MRR and Ra are inversely related machining characteristics and in case of non-ferrous materials these mainly depends upon input variables like: cutting speed, feed and depth of cut. Therefore in this study, optimisation of multi-response CNC turning parameters has been done by using central composite design technique of 'response surface methodology' (RSM) through Minitab 16 Software. Further statistical testing of results is verified through ANOVA. The paper discusses an experimental study on Al-7020 
alloy turned with un-coated carbide tip tool with a 'CNC TL-250 turner' that has a wide application in aerospace, machine tools and automobiles sector. It focuses more on software-based approach for implementing RSM on machining parameters, in contrast of conventional methods [10].

\section{RESEARCH GAP}

The high speed steel is most ordinarily utilized cutting instruments and they are equipped for cutting the metal at much higher rate than the carbon apparatus steel and keeps on cutting and hold its hardness notwithstanding when the purpose of hardware is warmed to a low red temperature. M2 review of HSS have great wear resistance, durability, machinability and its hardness is same as that of T1 review of HSS. It is normally used to produce an assortment of apparatuses, for example, boring tools, taps and reamers. Presently in this investigation the impact of release current, beat on time, crevice voltage and obligation cycle on the material expulsion rate, instrument wear rate and surface harshness can be gotten to subsequent to surveying the writing. Keeping in mind the end goal to improve the test comes about, utilization of Design of Experiments (full factorial or halfway), Taguchi's Method, RSM, Finite Element
Method and so on are adequately found in writing. The impact of every parameter were decide for the material, instrument and machining operations. A portion of the analyst set up the relationship between the reliant and autonomous machining parameters through this relapse models. In the wake of spurring from above review, an exertion has been made to bring the advancement of essential info parameters of the electric release machine (EDM) for rapid steel M2 review (AISI-M2) while machining with electronica's elecktra puls PS 50 which is kick the bucket sinking EDM.

\section{PROCESS VARIABLES AND THEIR LIMITS}

Process parameters has been decided by referring. Experimentations has been done by considering the following levels of process variables. These Table 1 process variables and their limits.

\begin{tabular}{|c|c|c|}
\hline Parameters & Lower limit & Upper limit \\
\hline $\begin{array}{c}\text { Discharge current } \\
\text { (Amp) }\end{array}$ & 4 & 40 \\
\hline Pulse-on-time ( $\boldsymbol{\mu s e c )}$ & 100 & 250 \\
\hline Gap voltage (V) & 3 & 6 \\
\hline Duty cycle(\%) & 1 & 11 \\
\hline
\end{tabular}

Table 1. Process variables and their limits

\begin{tabular}{|c|c|c|c|c|c|c|c|}
\hline StdOrder & RunOrder & PtType & $\begin{array}{c}\text { Discharge } \\
\text { current (Amp) }\end{array}$ & $\begin{array}{l}\text { Pulse on } \\
\text { time }(\mu s)\end{array}$ & $\begin{array}{l}\text { Gap voltage } \\
\text { (volt) }\end{array}$ & $\begin{array}{c}\text { Duty cycle } \\
(\%)\end{array}$ & $\begin{array}{c}\text { TWR } \\
\text { (gm/min) }\end{array}$ \\
\hline 13 & 1 & 1 & 4 & 100 & 6 & 11 & 0.012 \\
\hline 26 & 2 & 0 & 22 & 175 & 4.5 & 6 & 0.008 \\
\hline 16 & 3 & 1 & 40 & 250 & 6 & 11 & 0.002 \\
\hline 15 & 4 & 1 & 4 & 250 & 6 & 11 & 0.004 \\
\hline 18 & 5 & -1 & 58 & 175 & 4.5 & 6 & 0.016 \\
\hline 5 & 6 & 1 & 4 & 100 & 6 & 1 & 0.002 \\
\hline 10 & 7 & 1 & 40 & 100 & 3 & 11 & 0.032 \\
\hline 19 & 8 & -1 & 22 & 25 & 4.5 & 6 & 0.006 \\
\hline 25 & 9 & 0 & 22 & 175 & 4.5 & 6 & 0.004 \\
\hline 8 & 10 & 1 & 40 & 250 & 6 & 1 & 0.004 \\
\hline 29 & 11 & 0 & 22 & 175 & 4.5 & 6 & 0.006 \\
\hline 21 & 12 & -1 & 22 & 175 & 1.5 & 6 & 0.008 \\
\hline 9 & 13 & 1 & 4 & 100 & 3 & 11 & 0 \\
\hline 20 & 14 & -1 & 22 & 325 & 4.5 & 6 & 0 \\
\hline 24 & 15 & -1 & 22 & 175 & 4.5 & 16 & 0.008 \\
\hline 1 & 16 & 1 & 4 & 100 & 3 & 1 & 0 \\
\hline 7 & 17 & 1 & 4 & 250 & 6 & 1 & 0.002 \\
\hline 2 & 18 & 1 & 40 & 100 & 3 & 1 & 0.008 \\
\hline 14 & 19 & 1 & 40 & 100 & 6 & 11 & 0.032 \\
\hline 6 & 20 & 1 & 40 & 100 & 6 & 1 & 0.012 \\
\hline 22 & 21 & -1 & 22 & 175 & 7.5 & 6 & 0.006 \\
\hline 30 & 22 & 0 & 22 & 175 & 4.5 & 6 & 0.008 \\
\hline 31 & 23 & 0 & 22 & 175 & 4.5 & 6 & 0.018 \\
\hline 28 & 24 & 0 & 22 & 175 & 4.5 & 6 & 0.008 \\
\hline 12 & 25 & 1 & 40 & 250 & 3 & 11 & 0.002 \\
\hline 4 & 26 & 1 & 40 & 250 & 3 & 1 & 0.008 \\
\hline 3 & 27 & 1 & 4 & 250 & 3 & 1 & 0 \\
\hline 23 & 28 & -1 & 22 & 175 & 4.5 & -4 & 0.008 \\
\hline 27 & 29 & 0 & 22 & 175 & 4.5 & 6 & 0.006 \\
\hline 17 & 30 & -1 & -14 & 175 & 4.5 & 6 & 0.002 \\
\hline 11 & 31 & 1 & 4 & 250 & 3 & 11 & 0.004 \\
\hline
\end{tabular}

Table 2. Orthogonal matrix of response surface method 


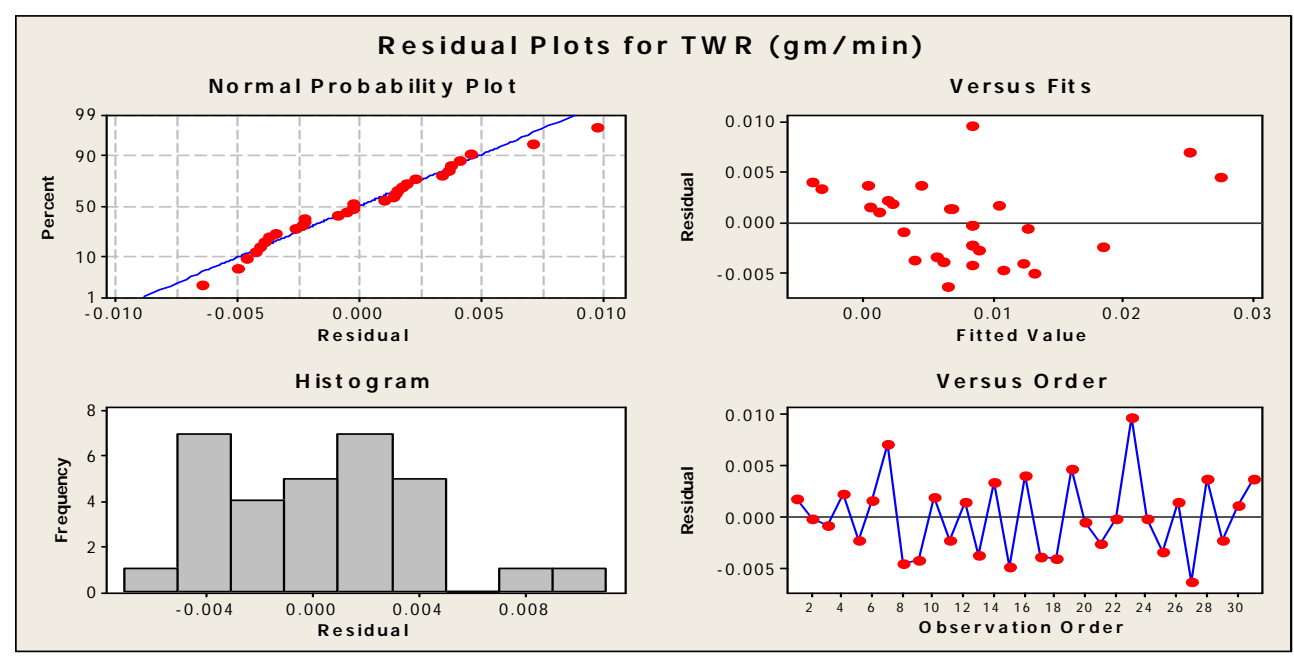

Fig. 2. data normality test for tool wear rate (TWR)

\section{ORTHOGONAL MATRIX OF RSM}

The investigations have been led utilizing reaction surface technique, trial outline which comprises of 31 blends of release current, beat on-time, voltage and obligation cycle. The analyses are executed according to the orthogonal grid produced by reaction surface technique with four variables and two levels while 0 blocking and reproduce estimation of 1 (allude table 2 for outlined analysis) of experimental order as far as second response tool wear rate (TWR) is concerned.

Reaction surface approach for instrument wear rate has been connected at $95 \%$ certainty, so all variables and their cooperations having p (likelihood) esteem under 0.05 will be factual huge for apparatus wear rate (TWR) and must be further dealt with. Allude table 4 . for more detail of measurable examination of RSM for TWR. As p qualities are more than 0.05 for (hole voltage $\times$ gap voltage) and (crevice voltage $\times$ duty cycle) and consequently can be disregarded amid enhancement of TWR on account of their unimportant explanatory impact. Coefficients speak to the relative effect of every component and its cooperations on TWR that have been dissected at $96.96 \%$ R-sq and Rsq (balanced) esteem.

\begin{tabular}{|lc|c|c|c|l|}
\hline Term & Coef & SE Coef & T & P & $\begin{array}{c}\text { Significant/ } \\
\text { Not significant }\end{array}$ \\
\hline Constant & 0.008286 & 0.001956 & 4.236 & 0.001 & Significant \\
\hline Discharge current(Amp) & 0.008667 & 0.002113 & 4.102 & 0.001 & Significant \\
\hline Pulse on time( $\mu$ s) & -0.007000 & 0.002113 & -3.314 & 0.004 & Significant \\
\hline Gap voltage(volt) & 0.001000 & 0.002113 & 0.473 & 0.046 & Significant \\
\hline Duty cycle(\%) & 0.004333 & 0.002113 & 2.051 & 0.037 & Significant \\
\hline Dis. current*dis. Current & 0.001381 & 0.003871 & 0.357 & 0.072 & Significant \\
\hline Pulse on time*Pulse on time & -0.004619 & 0.003871 & -1.193 & 0.025 & Significant \\
\hline Gap voltage*Gap voltage & -0.000619 & 0.003871 & -0.160 & 0.875 & Not Significant \\
\hline Duty cycle(\%)*Duty cycle(\%) & 0.000381 & 0.003871 & 0.098 & 0.023 & Significant \\
\hline Discharge current*pulse on time & -0.016000 & 0.005175 & -3.092 & 0.007 & Significant \\
\hline Discharge current*gap voltage & -0.004000 & 0.005175 & -0.773 & 0.045 & Significant \\
\hline Discharge current*duty cycle & 0.005000 & 0.005175 & 0.966 & 0.034 & Significant \\
\hline Pulse on time*Gap voltage & -0.005000 & 0.005175 & -0.966 & 0.084 & Significant \\
\hline Pulse on time*Duty cycle & -0.014000 & 0.005175 & -2.706 & 0.016 & Significant \\
\hline Gap voltage(volt)*Duty cycle(\%) & 0.002000 & 0.005175 & 0.387 & 0.704 & Not Significant \\
\hline R-Sq = 96.96\% & \multicolumn{2}{|c|}{ R-Sq(pred) $=90.26 \%$} & & \\
\hline
\end{tabular}

Table 3. statics for tool wear rate (TWR)

\section{GRAPHICAL INFERENCES FOR TOOL WEAR RATE (TWR)}

The software has deduced the result in graphical form also. The figure 3 highlights the one factor at a time effect on tool wear rate response. The first plot of figure 3 represents the increase in tool wear rate with rise of discharge current. The tool wear rate is directly proportional to the discharge current. If discharge current increases then tool wear rate is also increases with respect to it and if discharge current decreases then tool wear rate is also decreases. The second plot of figure is TWR versus pulse on time. In this figure the tool wear rate is increased firstly with rise in pulse on time upto $100 \mu$ s and then after $100 \mu$ s the tool wear rate start decreasing with increase in pulse on time and it become very low at $325 \mu$ s. The third plot of figure is TWR versus gap voltage.

The gap voltage does not have much effect on the tool wear rate. First when gap voltage increases upto 3 
volt the TWR decreases and after that if gap voltage is increases upto 6volt then the TWR start increases and in last when gap voltage increases upto 7.5 volt then TWR again become start decreasing and become least at 7.5volt. The fourth plot is TWR versus duty cycle which is very important as duty cycle is major parameter of EDM. In this plot TWR first decreases with increase in duty cycle upto $1 \%$ and after that TWR start increases rapidly from $1 \%$ to $11 \%$. And become maximum at $11 \%$.

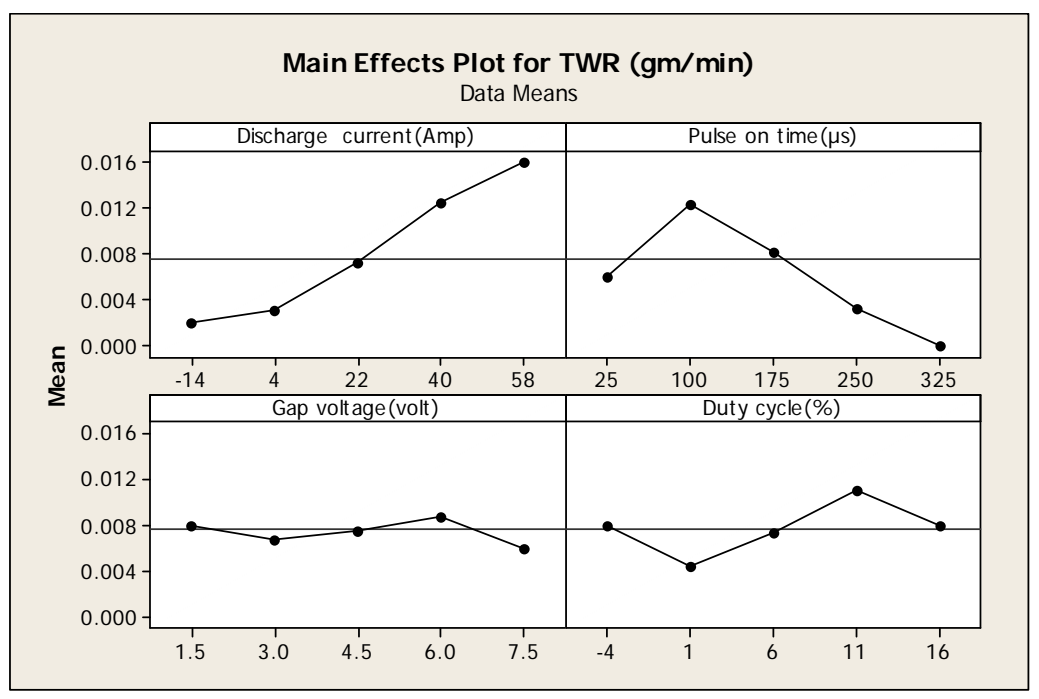

Fig. 3. main effect plots for TWR

\section{CONCLUSION}

In optimization of machining parameters generally taguchi's method is used but in the present case central composite design of response surface methodology (RSM) is being applied on electric discharge machine parameters for AISI-M2 high speed steel, successfully. The optimized result obtained by RSM are closely matched with actual one and further verified by ANOVA. The best combination of EDM parameters for AISI-M2 high speed steel are; discharge current 20.19 (Amp), pulse on time 221.96 ( $\mu \mathrm{s})$, gap voltage 3.56 (Volt) and duty cycle 16 (\%). It has been also found that individual parameters like discharge current and duty cycle are more influencing than other parameters like gap voltage and pulse on time.

\section{REFERENCES}

[1] S. H. Lee, X. P. Li,"Study of the effect of machining parameters on the machining characteristics in electrical discharge machining oftungsten carbide", J. Mater. Process Technol., 115 (2001), pp. 344-358.

[2] B. Bhattacharyya, S. Gangopadhyay, B. R. Sarkar,"Modelling and analysis of EDMed job surface integrity”, Journal of Materials Processing Technology, Vol. 189, pp. 169-177, 2007.

[3] Rahman M.M., Khan M.A.R., Kadirgama K., Noor M.M., Bakar R.A.,Experimental Investigation into Electrical Discharge Machining of Stainless Steel 304, Journal of Applied Sciences, 11: pp. 549-554.

[4] K. P. Rajurkar, S. M. Pandit,“Quantitative expressions for some aspects of surface integrity of electro discharge machined components”, Journal of Engineering for Industry, vol. 106, No. 2, pp. 171-177, 1984.

[5] B. Bhattacharyya, S. Gangopadhyay, B. R.
Sarkar,"Modelling and analysis of EDMed job surface integrity”, Journal of Materials Processing Technology, Vol. 189, pp. 169-177, 2007.

[6] D. Kanagarajan, R. Karthikeyan, K. Palanikumar, J. Paulo Davim, "Optimization of electrical discharge machining characteristics of WC/Co composite using non-dominated sorting genetic algorithm (NSGA-II)", Int. J. Adv. Manuf. Technol., 36 (2008), pp. 1124-1132.

[7] Rahman M.M., Khan M.A.R., Kadirgama K., Noor M.M., Bakar R.A.,Experimental Investigation into Electrical Discharge Machining of Stainless Steel 304, Journal of Applied Sciences, 11: pp. 549-554.

[8] Chen . S. L, Hsi eh . S. F, Li n. H. C, Li n. M. H, Huang J.S,"Electrical discharge machining of TiNiCr and TiNiZr ternary shape memory alloys", Materials Science and Engineering A 445-446 (2007) 186-492.

[9] Puertas I., Luis C.J., Alvarez L.,"Analysis of the influence of EDM parameters on surface quality, MRR and EW of WCCo", Journal of Materials Processing Technology, 153-154 (2004), pp. 10261032.

[10] Bikram Jit., Sodhi H S "Parametric optimisation of CNC turning for Al-7020 with RSM”IJOR ,Vol 20, No 2, PP 180-205.

Author: Mr Harsimran Singh Sodhi is Post Graduate in Production Engineering and Pursuing his $\mathrm{PhD}$. He is working as Assistant Professor in Mechanical Engineering Department of Chandigarh University Gharuan. Author is having a vast teaching experience of eight years. Authour is having more than twenty five publications in various international/ national conferences and International Journals. Key research areas of intrest of author are machining processes and industrial engineering.

E-mail: harsimransodhi86@gmail.com 